\title{
Extreme hypernatraemia in association with renal failure following caecocysto- plasty
}

\author{
W. S. WALKER* \\ F.R.C.S.(Edin)
}

\author{
C. J. THURSTON† \\ F.R.C.S.(Edin)
}

Department of General Surgery, Bangour General Hospital, Broxburn, West Lothian

\section{Summary}

A case of extreme hypernatraemia (serum sodium 212 mmol/l) occurring in asssociation with renal failure following a caecocystoplasty procedure is reported. The causative factors in extreme hypernatraemia are reviewed and an unusual reabsorptive mechanism via the transposed intestinal segment is proposed to explain the degree of hypernatraemia present in this case.

KEY WORDS: hypernatraemia, renal failure, caecocystoplasty.

\section{Introduction}

Hypernatraemia is a rare disorder, one recent study (Daggett et al., 1979) identifying only 20 cases out of 16,244 hospital admissions. Cases in excess of $200 \mathrm{mmol} / 1$ are extremely scarce, usually fatal, and almost always the result of salt poisoning (Goldszer and Coodley, 1979). To our knowledge, no previous report of such a degree of hypernatraemia exists in the British literature.

\section{Case report}

The patient, a 75-year-old woman, first presented with an 8-month history of urinary incontinence. Her plasma biochemistry at this time demonstrated a slight elevation in urea but was otherwise normal. Urine culture was sterile but an intravenous urogram (IVU) showed marked bilateral hydronephrosis and distal ureteric hold up which was seen at cystoscopy to be due to a fibrosed, shrunken bladder of very small capacity. Biopsy demonstrated an ulcerative cystitis with chronic inflammatory cell infiltrate. Her symptoms improved on emepronium bromide therapy and a repeat IVU showed marked decrease in the obstructive features. Ten months after first presentation, she was readmitted with worsened incontinence

\footnotetext{
*Present address: Edinburgh Royal Infirmary, Edinburgh.
}

†Present address: Royal Victoria Hospital, Kircaldy. and plasma biochemistry consistent with early renalo failure which however returned to normal with fluid therapy alone in a few days. Repeat cystoscopyoo confirmed the previous findings and, therefore, a caecocystoplasty was performed 1 year after first presentation to increase her bladder capacity.

Recovery was uneventful and she was allowedhome 18 days postoperatively with sterile urine and,, apart from a marginally elevated urea, virtuallyö normal plasma biochemistry. However 17 days later@ she was readmitted comatose, dehydrated and poripherally shut down. Her plasma biochemistry profoundly abnormal with gross elevation of sodiuf $\mathrm{n}^{+}$ and chloride and established renal failure: plasma sodium 212 , potassium $8 \cdot 1$, bicarbonate 11 , chlorides 151 , urea 68 , creatinine 0.718 , glucose $4.4 \mathrm{mmol} / 1$. Despite attempted resuscitation she died severalo hours later.

\section{Discussion}

Most cases of extreme hypernatraemia are associated with accidental sodium overload (Goldszer and Coodley, 1979), either orally, usually in hyperosmo-윽 lar infant feeds (Fineberg, Kiley and Luttrel, 1963) but occasionally with saline emetics, or parenterally을 as a complication of saline abortion or misguided electrolyte therapy. Profound dehydration may also윽 cause severe hypernatraemia, usually in children $>$ (Fineberg, 1973) and rarely in adults. Less severe hypernatraemia may occur in a variety of conditions N causing a greater loss of water than of salt such as diabetic ketoacidosis, gastroenteritis, the diuretic $\mathcal{O}$ phase of acute tubular necrosis and dialysis imba- $\omega$ lances.

In this case renal failure and dehyration wilko undoubtedly have contributed to sodium retention $\overparen{\varnothing}$ and a tendency to retain sodium will have been? promoted by any residual urinary obstruction 0 (Landsberg, 1970; Gold and Roxe, 1979). However, 
these factors do not appear adequate to explain the degree of hypernatraemia present-even in combination-on the basis of previous levels reported. Reabsorption of electrolyte is well described in ureterosigmoid anastomosis (Lowe, Stowers and Walker, 1959) and in ileal ureteric replacement (Goodwin, Winter and Turner, 1959). Studies of electrolyte transport in bladders augmented with ileal segments have shown free passage of electrolyte across the new bladder wall (Pyrah et al., 1955) and caecum will actively reabsorb sodium (Ganong, 1977).

Whilst this case is remarkable therefore by virtue of the sodium level recorded, it appears reasonable to propose an unusual possible mechanism which would seem to best explain the degree of sodium retention present. We suggest that equilibration of urinary to plasma sodium concentration across the caecal bladder wall segment, tending always to elevate the serum sodium towards the urine concentration and possibly beyond, could have occurred producing an excessive sodium load for the patient's impaired renal function. It is interesting to note that caecocystoplasty is not recommended in patients with impaired renal function (Skinner and Goodwin, 1975). Presumably, in normal individuals high fluid intake and adequate reserves of renal concentrating power would overcome such a sodium back diffusion effect which would not in any case become significant until some event produced a requirement for concentrated urine and therefore a need for high renal sodium excretion.

\section{Acknowledgment}

We are grateful to Mr I. W. J. Wallace, Consultant General and Urological Surgeon, Bangour General Hospital, Broxburn, West Lothian for his helpful criticism and permission to report this case.

\section{References}

Daggett, P., Deanfield, J., Moss, F. \& Reynolds, D. (1979) Severe hypernatraemia in adults. British Medical Journal, 1, 1170.

FineBERG, L. (1973) Hypernatraemic dehydration in infants. New England Journal of Medicine, 289, 196.

FiNEBERG, L., KILEY, J., LUTTREL, C.N. (1963) Mass accidental salt poisoning in infancy. Journal of the American Medical Association, 184, 187.

GANONG, N.F. (1977) Review of medical physiology. 8th edn. Lange Medical Publications, Los Altos, California.

GoLD, I. \& ROXE, D. (1979) Severe hypernatraemia caused by age, isolation and obstructive uropathy. Southern Medical Journal, 72, 1198.

Goldszer, R.C. \& Coodley, E.L. (1979) Survival with severe hypernatraemia, Archives of Internal Medicine, 139, 936.

GOODWIN, W.E., WINTER, C.C. \& TURNER, R.D. (1959) Replacement of the ureter by small intestine: clinical application and results of the "ileal ureter". Journal of Urology, 81, 406.

LANDSBERG, L. (1970) Hypernatremia complicating partial urinary tract obstruction. New England Journal of Medicine, 283, 746.

LOWE, K.G., STOWERS, J.M. \& WALKER, W.F. (1959) Electrolyte disturbances in patients with uretero-sigmoidostomy. Scottish Medical Journal, 4, 473.

SKINNER, D.G. \& GooDWIN, W.E. (1975) Indications for the use of intestinal segments in the management of nephrocalcinosis. Journal of Urology, 113, 436.

Pyrah, L.N., Care, A.D., Reed, G.N. \& Parson, F.M. (1955) The migration of sodium, chloride and potassium ions across the mucous membrane of the ileum. British Journal of Surgery, 42, 357.

(Accepted 29 September 1983) 